\title{
A NEW ERA OF MEDICAL BY ARTIFICIAL INTELLIGENCE
}

\author{
Devendra Kumar Mishra ${ }^{*}{ }^{\circledR}$, Shubham Shukla ${ }^{2}$ \\ ${ }^{* 1}$ Amity Institute of Pharmacy, Amity University Uttar Pradesh Lucknow Campus, India \\ 2 School of Biomedical and Pharmaceutical Sciences, Babasaheb Bhimrao Ambedkar University, \\ India
}

DOI: https://doi.org/10.29121/ijetmr.v7.i6.2020.700

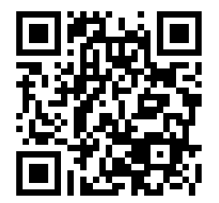

Article Citation: Devendra Kumar Mishra, and Shubham Shukla. (2020). A NEW ERA OF MEDICAL BY ARTIFICIAL INTELLIGENCE. International Journal of Engineering Technologies and Management Research, 7(6), 125-130. https://doi.org/10.29121/ijetmr.v7 .i6.2020.700

Published Date: 27 June 2020

Keywords:

Artificial Intelligence

Medication

Mhealth

Mams

Telemedicine

Telemonitoring

\section{ABSTRACT}

The multifaceted nature and climb of data in social protection suggest that artificial intelligence (system-based intelligence) will dynamically be applied inside the field. Overall restorative administrations have become components due to the changes in the human future. While attempting to beat repressions normal in the standard system helped investigation, authorities have made tasks that reenact ace human reasoning. A couple of sorts of AI are starting at now being used by payers and providers of care, and life sciences associations. The key classes of usages incorporate end and treatment proposition, calm responsibility and adherence, and definitive activities. The consistent extension of clinical information has made it increasingly hard for the doctor to stay side by side of medication outside a restricted field. There are various models where system-based intelligence can perform therapeutic administration endeavors likewise or better than individuals, execution parts will hinder gigantic degree automation of human administration capable occupations for a broad period. Offering more types of assistance in essential consideration and eventually in patient's homes could be viewed as a definitive objective for medicinal services conveyance and to a limited extent, this could be encouraged by intelligence.

\section{INTRODUCTION}

Artificial intelligence (system-based intelligence) is portrayed as a innovative area in the area of science and building interest about the computational appreciation of what is generally called insightful direct and with the creation of relics that show such conduct [1]. Projects which empower systems to work in the manners that cause individuals to appear to be shrewd are called as AI systems [2]. The first dynamically assessment of AI in the field of clinical method was seen in 1976 by the Gunn, by researching the diagnosing extraordinary stomach torment with system investigation [3]. It is intended to imitate the layers of neurons in the human cerebrum to process and concentrate data [4], permitting systems to learn without being expressly modified [5]. This method can likewise be conceivably used to recognize maladies, including retinal sicknesses from fundus images, identification of tuberculosis with the help of radiographs of chest [6], [7], [8], and visual of skin images for threatening melanoma [9]. All the more as of late, profound learning has been used to distinguish chance elements related to cardiovascular maladies (for instance, pulse, smoking, and weight file) from retinal photographs [10]. Today, computer-based intelligence is viewed as a part of designing that executes complex difficulties to mimic the role of human brain. AI getting the high progress in the terms of electronic speed, limit, and programming, systems may some time it will as

(C) 2020 The Author(s). This is an open access article distributed under the terms of the Creative Commons Attribution License, which permits unrestricted use, distribution, and reproduction in any medium, provided the original author and source are credited. 
clever as people and perform the process smoothly. One can't disregard the significant commitment of contemporary robotics to the advancement of $\mathrm{AI}$ [11]. The consistent extension of clinical information has made it increasingly hard for the doctor to stay side by side of medication outside a restricted field.

Early, when there was no AI concepts at that time there are several clinical issue lies which were faced by the doctor's, yet habitually master feeling is either inaccessible or not accessible in an ideal manner. Endeavors have been made to create system programs that can fill in as specialists [12], [13], [14]. Examiners at that point started to contemplate the master doctor to acquire definite experiences into the fundamental idea of clinical critical thinking [15], [16]. The outcomes got from such investigations have hence shaped the reason for computational models of the subjective wonders, and these models have moreover been changed over into supposed AI programs [17], [18], [19]. The aim of this paper to offer a brief review on the advancement within the savvy information about the medication, through artificial intelligence and a view on some current, also future patterns that enhanced the medical field.

\section{HISTORICAL OVERVIEW}

When electronic PCs came into utilization during the 1930s and 1960s, the calculations were built up that empowered displaying and examining enormous arrangements of information. AI is much more take the interest from the beginning. From the earliest starting point, three significant parts of AI rose. Old style work in emblematic learning is portrayed [20], in factual strategies [21], and neural systems [22]. As the years progressed, every one of the three branches created propelled strategies [23]: factual or design acknowledgment techniques, for example, the discriminant investigation, and Bayesian classifiers, inductive learning of emblematic principles, for example, topdown enlistment of choice trees, choice standards and acceptance of rationale programs, and neural systems of artificial [24].

\section{AI IN MEDICATION}

\subsection{THE VIRTUAL CONCEPT}

The implementation of $\mathrm{AI}$ in medication follows the two fundamental concepts: virtual and physical. The virtual part of $\mathrm{AI}$ in medication is based on the Machine Learning, (which is also known as the Deep Learning) which performed in respect to the numerical calculations that improve understanding through learning. In terms of AI calculation it is of three kinds:

- Unaided (capacity to discover designs),

- Directed (order and expectation calculations dependent on past models),

- Support learning (utilization of successions of remunerations and disciplines to shape a system for activity in a particular issue space) [25]. A case of triumphs in medication is the unaided protein-protein connection calculations that prompted novel restorative objective disclosures [26].

\subsection{THE PHYSICAL CONCEPT}

The second kind of utilization of system based insight in medicine fuses physical articles, clinical devices and logically robots participating in the consideration (carebots) [27]. Perhaps the most encouraging methodology is the use of robots as collaborators; for instance, a robot accomplice for the developing masses with mental lessening or obliged flexibility. Japanese carebots are the one of promising example in the field of AI. Now a day, the robots were started being utilized in clinical methodology [28]. Besides moral issues, a huge test in this new component of clinical thought is the sensible for normalized, relative assessment of the impact of mechanical structures on prosperity markers, and extents of changes in physical and mental status, their responses, as well also the results of it [29].

\section{USE OF MEDICATION ADHERENCE MANAGEMENT SYSTEM (mAMS) ON BASIS OF MOBILE HEALTH (MHEALTH)}

A crucial fundamental for viable treatment is the comprehension and co-advancement of person illness as shown by typical confirmation of got a handle on drugs (adherence). In terms of enlighten person illness about their 
Devendra Kumar Mishra, and Shubham Shukla

prescription confirmation and to overhaul their adherence, we have developed a mHealth based mAMS [30]. A mAMS was set up to screen fair-mindedly a patient's quick in taking the maintained medication and in this manner to check and, if lacking, to improve his/her adherence by methods for shut circle affiliations. The structure utilized fundamental information and correspondence advancements (Web and wireless applications) similarly as introduced accurate counting of the numbers of pills taken by the person by the help of microelectronic parts (counting printed devices). This structure fragments were used by patients and specialists for better outcomes [31]. As per the Prescription Adherence Model, patients purposefully intake medicine dependent to their need not on the prescription, viability, and wellbeing and keep on taking drugs through access, schedule, and recollecting [32]. Likewise, prescription nonadherence is extensively named purposeful and accidental [33], [34]. Nonadherent practices cause almost of larger population of 33-69\% patients or affected one of medicine-related hospitalizations and that results in the huge amount of cost ever year of 100 billion dollars [33].

\subsection{REMOTE TELEMONITORING ADMINISTRATION}

An online telehealth framework got the information sent from the cell phone and dismembered points of view which includes the ill person had taken the medication or not and if taken then it record the timing of it, as when the patient taken the pills. The AI also uses as the reminder facilities for those patient who are having the problem to forget anything. AI also helps in the telenursing, and other useful criteria. Information was introduced to the investigation doctor numerically and graphically through program-based UI [30].

\section{TELEMEDICINE}

Telemedicine is a tremendous subject, yet so far there obliged data on the clinical sufficiency and cost adequacy of most telemedicine applications. In this way, target information about the points of interest and drawbacks of telemedicine is obliged [35]. Telemedicine is an assorted assortment of advancements and clinical applications. The characterizing part of telemedicine is the utilization of electronic signs to move data starting with one site then onto the next. Numerous zones of clinical practice have potential telemedicine applications. Telemedicine is viewed as an apparatus that could help deal with the clinical and monetary dangers of giving patient consideration in rustic and underserved regions. Suppliers with telemedicine capacities are wanting to turn out to be increasingly serious in winning medicinal services contracts, to decrease the monetary and clinical dangers related with thinking about patients in country zones, and to give generally minimal effort forte administrations to zones where full-time staffing is unfeasible or uneconomical [36].

\subsection{REDUCED HEALTH-CARE COSTS}

Enormous scope preliminaries presently can't seem to be completed for most telemedical applications. In the long haul, telemedicine could drastically decrease the general expenses of wellbeing administrations in light of its capability to permit a crucial rebuilding of the manner in which medicinal services are conveyed. This would mainly come about because of redistributing assets from the medical clinic condition into an essential consideration. Offering more types of assistance in essential consideration and eventually in patients homes could be viewed as a definitive objective for medicinal services conveyance and to a limited extent, this could be encouraged by telemedicine [35].

\section{CURRENT PATTERNS OF INTELLIGENCE IN MEDICAL}

It has been hard for some patients to arrive at emergency clinics in the lockdown time frame. Thus for the ease and support in these critical situation of patients, numerous emergency clinics have begun for example telemedicine outpatient administrations. Cell phone innovation permits remote counsel, guidance, and consolation. Cell phone innovation along these lines helps in appraisal, triage, finding, and arranging further administration [37], [38]. With the impacts of 'self-confinement' and 'protecting' on Psychological well-being during the COVID-19 pandemic, the low state of mind and wretchedness has been recognized. Cell phone innovation can help in emotional wellness guidance and advising to console ill person and along these lines offer help [39]. COVID-19 has had a noteworthy 
impact on instruction and preparation. As practically totally booked gatherings, classes, different types of workshops and other educational activities have been started with the engagement with the AI, that's helps in the bounding of all over together on same platform and also some of online courses called 'online classes' has extended enormously and viably available with wireless communication development. Instructive establishments have been shut down and instructors have been taking talks on the web. Understudies are getting to these talks online through the assistance of cell phones which were also now terms as the lifeline for the researcher, student, patients, and other medical field person for the better communication and the engagement and reliability on the system based intelligence for their wellbeing [40].

\section{FUTURE IMPRESSION OF INTELLIGENCE IN MEDICAL}

We acknowledge that artificial intelligence has a critical errand to do in the therapeutic administration's commitments of what might be on the horizon. Like AI, it is the basic limit behind the improvement of precision prescription, for the most part, assented to be a woefully required advancement in healthcare. Yet early undertakings at giving conclusion and treatment suggestions have exhibited testing, we expect that intelligence will in the long run pro that zone too [41]. Computerized reasoning has quite recently begun to change the condition of social protection. In any case, there are various nuances and moves that ought to be tended to before its utilization to the clinical practice. Now rules nonappearance of checks to assess the prosperity and ampleness of artificial intelligence counts. Prior to joining artificial intelligence and ML into clinical practice, authoritative ought to be comprehended. Properly FDA endeavored to direct how to survey and execute system-based intelligence all things considered wellbeing things [42]. The inaccessible future emotional systems will help clinicians in their dynamic and choosing anticipating patient results. The tremendous proportion of data made by scheduling each day work-up requires utilization of system-based intelligence into preparing. We recently observed the snappy change of procedure vision in pathology and radiology. It is noteworthy not to fear man-made intelligence anyway to clutch it as the prosperity ends up being progressively. System based intelligence will give clinicians the skill to disentangle calm level data in more essential significance than whenever in ongoing memory [43].

\section{CONCLUSION}

Artificial intelligence for singular use will stay with us much as genetic characteristics will continue offering singular kinds of help. It is thusly basic to consider how system-based intelligence will in like manner serve the progression of our social protection systems. AI has redesigned clinical investigation and dynamic execution in a couple of clinical endeavor spaces. System based intelligence has exhibited to have a beneficial outcome on the decline in death rates by improving the adequacy of disorder discovering, disease the administrators, and treatment. Artificial intelligence is a promising inventive movement that ensures a change in the social protection structure for a predominant future in the business. The advancement is a vexed in the overall social protection system as its points of interest by far surpass the potential troubles and fears. At this moment, artificial intelligence in blend in with robots has incited positive changes in care, without a replacement of the human pros and clinical overseers. In the long haul, telemedicine could drastically decrease the general expenses of wellbeing administrations in light of its capability to permit a crucial rebuilding of the manner in which medicinal services are conveyed. Now the future impression of intelligence in medical were broadly depends on the new pathway to approach the ill person at their own area that results in to the saving of time and cost as well the faster treatment. Now AI also involve in the AI based assessment of the body or any diseases factor and on basis of it, the AI recommend the doctor information and also in few cases medication which was not serious concern.

\section{SOURCES OF FUNDING}

None.

\section{CONFLICT OF INTEREST}

None. 
Devendra Kumar Mishra, and Shubham Shukla

\section{ACKNOWLEDGMENT}

None.

\section{REFERENCES}

[1] Shapiro SC, Encyclopedia of artificial intelligence, 2 ed, New York: Wiley; 1992.

[2] Turing AM, Computing machinery and intelligence, Mind, 1950;59:433-60.

[3] Gunn AA, The diagnosis of acute abdominal pain with computer analysis, J R Coll Surg Edinb, 1976;21:1702.

[4] Ting DSW, Cheung CY, Lim G, Tan GSW, Quang ND, Gan A, et al, Development and Validation of a Deep Learning System for Diabetic Retinopathy and Related Eye Diseases Using Retinal Images from Multiethnic Populations With Diabetes, JAMA, 2017;318(22):2211-23.

[5] Kermany DS, Goldbaum M, Cai W, Valentim CCS, Liang H, Baxter SL, et al, Identifying Medical Diagnoses and Treatable Diseases by Image-Based Deep Learning, Cell, 2018;172(5):1122-31.

[6] Burlina PM, Joshi N, Pekala M, Pacheco KD, Freund DE, Bressler NM, Automated Grading of Age-Related Macular Degeneration from Color Fundus Images Using Deep Convolutional Neural Networks, JAMA Ophthalmol, 2017;135(11):1170-6.

[7] Lakhani P, Sundaram B, Deep learning at chest radiography: Automated Classification of Pulmonary Tuberculosis by Using Convolutional Neural Networks, Radiology, 2017;284:574-82.

[8] Ting DSW, Yi PH, Hui F, Clinical Applicability of Deep Learning System in Detecting Tuberculosis with Chest Radiography, Radiology, 2018;286:729-31.

[9] Esteva A, Kuprel B, Novoa RA, Ko J, Swetter SM, Blau HM, et al, Dermatologist-level classification of skin cancer with deep neural networks, Nature, 2017;542(7639):115-8.

[10] Poplin R, Varadarajan AV, Blumer K, Liu Y, McConnell MV, Corrado GS, et al, Prediction of cardiovascular risk factors from retinal fundus photographs via deep learning, Nat Biomed Eng, 2018;2(3):158-64.

[11] Wiener N, Cybernetics: or control and communication in the animal and the machine, Paris: JSTOR; 1948.

[12] Schwartz WB, Medicine and the computer: the promise and problems of change, N Engl J Med, 1970;283:1257-64.

[13] Lusted LB, Introduction to Medical Decision Making, Springfield, Illinois:Thomas; 1968.

[14] Jacquez J A, ed, Computer Diagnosis and Diagnostic Methods, Springfield; Illinois: Thomas; 1972.

[15] Gorry GA, Computer-assisted clinical decision making, Methods Inf Med, 1973;12:45-51.

[16] Kassirer JP, Gorry GA, Clinical problem solving: a behavioral analysis, Ann Intern Med, 1978;89:245-55.

[17] Elstein AS, Shulman LS, Sprafka SA, Medical Problem Solving: An Analysis of Clinical Reasoning, Cambridge: Harvard University Press; 1978.

[18] Shortliffe, EH, Computer-Based Medical Consultations: MYCIN, New York: Elsevier; 1976.

[19] Miller RA, Pople HE JR, Myers JD, Internist-1, an experimental computer-based diagnostic consultant for general internal medical, NEngl J Med, 1982;307:468-76.

[20] Mitchell T, Machine learning, New York: McGraw-Hill, 1997.

[21] Nilsson N, Learning machines, New York: McGraw-Hill, 1963.

[22] Rosenblatt F, Principles of neurodynamics, Washington, DC: Spartan Books, 1962.

[23] Michie D, Spiegelhalter DJ, Taylor CC, editors, Machine learning, neural and statistical classification, Chichester, UK: Ellis Horwood, 1994.

[24] Kononenko I, Bratko I, Kukar M, Application of machine learning to medical diagnosis, In: Michalski RS, Bratko I, Kubat M, editors, Machine learning, data mining and knowledge discovery: methods and applications, New York: Wiley, 1998.

[25] Hamet P, Tremblay J, Artificial intelligence in medicine, Metabolism, 2017;69: S36-S40.

[26] Theofilatos K, Pavlopoulou N, Papasavvas C, Likothanassis S, Dimitrakopoulos C, Georgopoulos E, et al, Predicting protein complexes from weighted protein-protein interaction graphs with a novel unsupervised methodology: evolutionary enhanced Markov clustering, Artif Intell Med, 2015;63(3):181-9.

[27] Cornet G, Robot companions and ethics a pragmatic approach of ethical design, J Int Bioethique, 2013;24(4):49-58. 
[28] Larson JA, Johnson MH, Bhayani SB, Application of surgical safety standards to robotic surgery: five principles of ethics for nonmaleficence, J Am Coll Surg, 2014; 218(2):290-3.

[29] Knight BA, Potretzke AM, Larson JA, Bhayani SB, comparing expert reported outcomes to National Surgical Quality Improvement Program risk calculator-predicted outcomes: do reporting standards differ, J Endourol, 2015;29(9):1091-9.

[30] Brath H, Morak J, Kastenbauer T, Modre-Osprian R, Strohner-Kastenbauer H, Schwarz M, et al, Mobile health (mHealth) based medication adherence measurement - a pilot trial using electronic blisters in diabetes patients, Br J Clin Pharmacol, 2013;76(1):47-55.

[31] Morak J, Schwarz M, Hayn D, Schreier G, Feasibility of mHealth and near field communication technologybased medication adherence monitoring, Conf Proc IEEE Eng Med Biol Soc, 2012;2012:272-5.

[32] Johnson MJ, the medication adherence model: A guide for assessing medication taking, Res Theory Nurs Pract, 2002;16:179-192.

[33] Dayer L, Heldenbrand S, Anderson P, et al, Smartphone medication adherence applications: Potential benefits to patients and providers, J Am Pharm Assoc, 2013;53:172-181.

[34] Wroe AL, Intentional and unintentional nonadherence: A study of decision making, J Behav Med, 2002;25:355-372.

[35] Hjelm NM, Benefits and drawbacks of telemedicine, Journal of Telemedicine and Telecare, 2005;11(2):6070.

[36] Douglas A, Perednia M, Ace Allen, MD, Telemedicine Technology and Clinical Applications, JAMA Network, 1995;273:483-8.

[37] Greenhalgh T, Vijayaraghavan S, Wherton J, Shaw S, Byrne E, Campbell-Richards D, et al, Virtual online consultations: advantages and limitations (VOCAL) study, BMJ Open, 2016;6(1): e009388.

[38] Greenhalgh T, Wherton J, Shaw S, Morrison C, Video consultations for covid-19, BMJ, 2020;368:1-2.

[39] Iyengar K, Upadhyaya GK, Vaishya R, Jain V, COVID-19 and applications of smartphone technology in the current pandemic, Diabetes Metab Syndr, 2020;14(5):733-7.

[40] J, Sandars, R, Correia, M, Dankbaar, P, de Jong, et al, twelve tips for rapidly migrating to online learning during the COVID-19 pandemic, MedEdPublish, 2020;9:82.

[41] Davenport T, Kalakota R, The potential for artificial intelligence in healthcare, Future Healthcare Journal, 2019;6(2):94-8.

[42] Graham J, Artificial Intelligence, Machine Learning, and the FDA, Available from: URL: https://www, forbes, com/sites/ theapothecary/ 2016/ 08/ 19/artificial- intelligence- machine learning-and- the- fda/\# 4aca26121aa1, Accessed on 17-June-2020.

[43] Tekkesin AI, Artificial Intelligence in Healthcare: Past, Present and Future, Anatol J Cardiol, 2019;22(2):8-9. 